SCIENTIFIC REPORT

\title{
The relation of Graves' ophthalmopathy to circulating thyroid hormone status
}

\author{
J M Kim, L LaBree, L Levin, S E Feldon
}

Br J Ophthalmol 2004;88:72-74

\begin{abstract}
Aim: The risk factors and epidemiological data for Graves' ophthalmopathy with and without abnormal circulating thyroid levels were examined to determine the relation of thyroid dysfunction to ophthalmopathy.

Methods: The authors retrospectively evaluated 482 patients seen with Graves' ophthalmopathy. Of these, 413 were classified as having abnormal levels of circulating thyroid hormone (ALTH) and 69 as having normal levels of circulating thyroid hormone (NLTH).

Results: Patients in the NLTH group, compared to the ALTH group, were older on average (56 (SD 13.5) v 52 (15.4)) and had a higher age adjusted body mass index (26.1 (0.8) $v 23.4$ (0.3)). In addition, a higher percentage of NLTH patients had hypercholesterolaemia. Those in the ALTH group were more likely to be female (76\% v 51\%), to have a family history of thyroid problems, and to have had eye surgery.

Conclusion: NLTH and ALTH appear to differ from each other in terms of risk factors and epidemiological characteristics. Additionally, thyroid dysfunction seems to be associated with a more severe ophthalmopathy compared to the euthyroid state.
\end{abstract}

$\mathrm{T}$ he relation of Graves' ophthalmopathy to thyroid disease is poorly understood although the orbital changes are generally regarded as autoimmune in origin. ${ }^{1-4}$ Between $80-90 \%$ of patients with Graves' ophthalmopathy have associated hyperthyroidism, ${ }^{56}$ but there is a subset of patients who are euthyroid. ${ }^{78}$ Solomon et al proposed that Graves' ophthalmopathy, Graves' hyperthyroidism, and Hashimoto's thyroiditis are separate and distinct autoimmune disorders that tend to occur in pairs. ${ }^{7}$ Supporting this proposal, Inoue et al found that the HLA types of patients with euthyroid Graves' ophthalmopathy are genetically distinct from those of patients with Graves' disease or Hashimoto's thyroiditis. ' However, others have cited endocrinological, immunological, and clinical evidence to the contrary. ${ }^{10-13}$

As more sensitive tests become available perhaps most, if not all, of these patients will be found to manifest thyroid abnormalities. Thus, it is unlikely that there are two separate entities-dysthyroid ophthalmopathy and euthyroid ophthalmopathy. Yet, the fact that euthyroid patients do develop eye changes affords the opportunity to evaluate the relation between thyroid hormone abnormalities and their specific association with eye disease.

In the present study, we retrospectively evaluated possible risk factors as well as various clinical variables associated with both abnormal thyroid hormone (ALTH) and normal thyroid hormone (NLTH) status in 482 consecutive patients seen at the Doheny Eye Institute, Keck School of Medicine.

\section{METHODS}

We reviewed all retrievable charts of patients initially seen at our institution for Graves' ophthalmopathy between the years of 1980-99. Ophthalmopathy was diagnosed by a combination of clinical symptoms and signs and computed tomographic scans. Of a total of 482 patients, 413 were classified as having ophthalmopathy associated with some form of thyroid dysfunction (dysthyroid group, ALTH), as evidenced by a history of abnormal thyroid function tests, previous diagnosis of thyroid dysfunction by an outside physician, or current or past use of thyroid medications. Of these 413 patients, 401 had a documented history of Graves' hyperthyroidism. Hashimoto's was previously diagnosed in four in which two also had Graves' disease. Eight had a history of hypothyroidism of unknown aetiology. The remaining 69 patients were found to be euthyroid, based on the normal thyroid function tests, lack of clinical signs or symptoms, absence of medical or surgical treatment for thyroid dysfunction, and a negative history of any thyroid associated abnormalities. These NLTH patients were often seen many times in our neuro-ophthalmology clinic and their thyroid status was continuously monitored for any evidence of dysfunction. Any NLTH patients who subsequently developed thyroid dysfunction were reclassified into the appropriate group. We cannot exclude the possibility that some NLTH patients had an undetected, transient episode of asymptomatic hyperthyroidism.

Independent sample $t$ tests were used to compare the means of the continuous variables between groups. $\chi^{2}$ or Fisher's exact tests were used to test for differences in the frequencies of the categorical variables between groups. Variables for which there were found to be statistically significant differences between groups were subjected to stepwise logistic regression to determine which variables were independently predictive of group assignment.

We calculated the means and frequencies for the significant risk factors and epidemiological data and compared them with those of the NLTH and the hyperthyroid groups. Independent sample $t$ tests were used to compare the means of the continuous variables between groups. $\chi^{2}$ or Fisher's exact tests were used to test for differences in the frequencies of the categorical variables between groups.

\section{RESULTS}

Characteristics of the 12 patients with a history of hypothyroidism tended to be more similar to the hyperthyroid group than to NLTH group and, therefore, were assigned to the ALTH category (table 1). The mean age at first neuroophthalmology visit was higher for the NLTH group (56 (SD 13.5)) than for the ALTH group $(52(15.4))(\mathrm{p}=0.02)$. The patients in the NLTH group were on average heavier than patients in the ALTH group (age adjusted BMI = 26.1 (SD 0.8 ) and $23.4(0.3)$, respectively, $p=0.001)$. Seventy six per cent of the ALTH group was female compared to $51 \%$ for the NLTH group $(\mathrm{p}<0.001)$. The ALTH group had a higher 
Table 1 Comparison of hypothyroid, hyperthyroid, and euthyroid groups

\begin{tabular}{|c|c|c|c|}
\hline & $\begin{array}{l}\text { Hypothyroid group } \\
(n=12)\end{array}$ & $\begin{array}{l}\text { Hyperthyroid group } \\
(n=401)\end{array}$ & $\begin{array}{l}\text { Euthyroid (NLTH) group } \\
\text { ( } \mathrm{n}=69 \text { ) }\end{array}$ \\
\hline $\begin{array}{l}\text { Age (years) at first neuro- } \\
\text { ophthalmology visit }\end{array}$ & $58.7(10.6)$ & $51.8(15.5)$ & $56.0(13.5)$ \\
\hline $\begin{array}{l}\text { Versus hypothyroid group ( } t \text { test } p \\
\text { value) }\end{array}$ & & 0.13 & 0.52 \\
\hline $\mathrm{BMI}$ & $23.4(2.9)$ & $23.4(4.1)$ & $26.3(5.6)$ \\
\hline $\begin{array}{l}\text { Versus hypothyroid group ( } t \text { test } p \\
\text { value) }\end{array}$ & & 1.00 & 0.20 \\
\hline BMI, age adjusted (mean (SE)) & $23.3(1.5)$ & $23.4(0.3)$ & $26.1(0.8)$ \\
\hline $\begin{array}{l}\text { Versus hypothyroid group ( } t \text { test } p \\
\text { value) }\end{array}$ & & 0.93 & 0.16 \\
\hline \multicolumn{4}{|l|}{ Sex } \\
\hline Male & $1(8 \%)$ & $97(24 \%)$ & $34(49 \%)$ \\
\hline Female & $11(92 \%)$ & $304(76 \%)$ & $35(51 \%)$ \\
\hline $\begin{array}{l}\text { Versus hypothyroid group (Fisher's } \\
\text { exact test } p \text { value) }\end{array}$ & & 0.31 & 0.01 \\
\hline $\begin{array}{l}\text { Family history of thyroid disease } \\
\text { Versus hypothyroid group (Fisher's } \\
\text { exact test } p \text { value) }\end{array}$ & $2(17 \%)$ & $\begin{array}{l}97(24 \%) \\
0.74\end{array}$ & $\begin{array}{l}7(10 \%) \\
0.62\end{array}$ \\
\hline
\end{tabular}

percentage of patients who had eye surgeries $(p=0.004)$ or a family history of thyroid disease $(p=0.01)$, while the NLTH group had a higher percentage of patients with hypercholesterolaemia $(p=0.006)$. No significant differences were found for other variables as listed in table 2. Stepwise logistic regression revealed that sex, a history of eye surgery, hypercholesterolaemia, age at first ocular dysfunction, and family history of thyroid disease were independently predictive of group assignment with $\chi^{2} \mathrm{p}$ values of 0.0001 , $0.0009,0.002,0.006,0.03$, respectively.

\section{Data analysis}

Generalisability of the study population

The relative frequency of NLTH in this study is similar to the $10 \%-20 \%$ reported by others, ${ }^{5}{ }^{6}$ as is the approximate $3: 1$ ratio of female:male patients for ALTH and the approximate 1:1 ratio for NLTH. ${ }^{5614}{ }^{15}$ The age distribution was also similar to the findings of previous studies with a mean age in the ALTH and NLTH groups of 52 and 56, respectively ${ }^{513}$ (table 2). Thus, no important bias in the patient population due to unusual patterns of referral was found.

\section{Comparison of risk factors}

Risk factors may be grouped into two types-vasculopathic and endocrinopathic. The NLTH group had significantly higher risk indices for vasculopathic risk factors of age, BMI, and hypercholesterolaemia but no instances of significantly lower risk indices relative to the ALTH group. However, the prevalence of hypercholesterolaemia, diabetes, hypertension, and tobacco use did not exceed that of the general population for either the ALTH or the NLTH groups. ${ }^{16-19}$ Given that the NLTH group did not exceed these predicted prevalences in the general population, differences in the BMI and total cholesterol between the two groups may be

Table 2 Data recorded for ALTH and NLTH groups

\begin{tabular}{|c|c|c|c|}
\hline & ALTH group $(n=413$ ) & NLTH group $(n=69)$ & p Value \\
\hline Age (years) at first neuro-ophthalmology visit & $52.0(15.4)$ & $56.0(13.5)$ & 0.02 \\
\hline Age (years) at first ocular dysfunction & $49.0(15.6)$ & $54.4(13.4)$ & 0.004 \\
\hline $\begin{array}{l}\text { Difference between age at } 1 \text { st neuro- } \\
\text { ophthalmology visit and } 1 \text { st ocular dysfunction }\end{array}$ & $2.7(5.3)$ & $1.3(2.5)$ & 0.02 \\
\hline BMI & $23.4(4.0)$ & $26.3(5.6)$ & $<0.001$ \\
\hline Age adjusted (mean (SE)) & $23.4(0.3)$ & $26.1(0.8)$ & 0.001 \\
\hline \multicolumn{4}{|l|}{ Sex } \\
\hline Male & $98(24 \%)$ & $34(49 \%)$ & $<0.001$ \\
\hline Female & $315(76 \%)$ & $35(51 \%)$ & \\
\hline \multicolumn{4}{|l|}{ Race } \\
\hline White & $249(60.3 \%)$ & $43(62.3 \%)$ & 0.34 \\
\hline African-American & $27(6.5 \%)$ & $2(2.9 \%)$ & \\
\hline Hispanic & $31(7.5 \%)$ & $9(13.0 \%)$ & \\
\hline Asian & $43(10.4 \%)$ & $4(5.8 \%)$ & \\
\hline Other & $63(15.3 \%)$ & $11(15.9 \%)$ & \\
\hline Medical treatment for ophthalmopathy & $140(34 \%)$ & $17(25 \%)$ & 0.17 \\
\hline Eye surgery & $217(53 \%)$ & $23(33 \%)$ & 0.004 \\
\hline Autoimmune & $17(4 \%)$ & $5(7 \%)$ & 0.23 \\
\hline Family history thyroid disease & $99(24 \%)$ & $7(10 \%)$ & 0.01 \\
\hline $\begin{array}{l}\text { History of radiation treatment for Graves' } \\
\text { ophthalmopathy }\end{array}$ & $18(4 \%)$ & $1(1.5 \%)$ & 0.50 \\
\hline Hypercholesterol & $31(7.5 \%)$ & $13(19 \%)$ & 0.006 \\
\hline \multicolumn{4}{|l|}{ Surgeries } \\
\hline Decompression & $100(24 \%)$ & $5(7 \%)$ & $<0.001$ \\
\hline Strabismus & $208(50 \%)$ & $18(26 \%)$ & $<0.001$ \\
\hline Levator & $88(21 \%)$ & $5(7 \%)$ & 0.005 \\
\hline Lower lid retraction & $35(8 \%)$ & $5(7 \%)$ & 1.00 \\
\hline Blepharoplasty & $64(16 \%)$ & $7(10 \%)$ & 0.28 \\
\hline
\end{tabular}


attributable to the effects of a recent hyperthyroid state. ${ }^{20-24}$ It is notable that the NLTH group had a higher average BMI than the general population. ${ }^{25}$ On the other hand, the ALTH group had significantly greater endocrinopathic risk factors than the NLTH group (female sex and positive family history of thyroid disease). Similarity of racial make-up between the groups may suggest similarity of underlying immunological response characteristics in the two groups (table 2 ).

\section{Severity of ophthalmopathy}

If surgical treatment is taken as an indication of the degree of ophthalmopathy, NLTH was found to be a less severe disease than ALTH. Also, those patients with NLTH tended towards less medical and radiation treatment than patients with ALTH (table 2). This is in agreement with Solomon's observation of milder eye disease in patients with euthyroid versus patients with dysthyroid Graves' ophthalmopathy. ${ }^{9}$

\section{DISCUSSION}

This study is the largest such series yet reported. Those patients in the NLTH group were significantly older, more likely to be male, had less severe ophthalmopathy, a higher BMI (even relative to the general population), and a lower incidence of a family history of thyroid disease than the patients in the ALTH group. Therefore, ALTH and NLTH appear to have different risk factors as well as epidemiological characteristics, indicating that NLTH may deserve its separate status.

Of high clinical relevance, the ALTH group had a higher incidence of surgical treatments, indicating more severe ophthalmopathy. This implies that thyroid status is probably influential in determining the clinical course of ophthalmopathy. That thyroid dysfunction is associated with increasing severity of ophthalmopathy is corroborated by previous studies. ${ }^{7627}$ Also, high serum thyrotropin concentrations or hypothyroidism after radioiodine therapy are associated with an increased risk of ophthalmopathy. ${ }^{28}{ }^{29}$ Thus, strict normalisation of thyroid function may be beneficial in lessening the severity of ophthalmopathy.

\section{ACKNOWLEDGEMENTS}

Supported in part by NIH grant EY03040 and by unrestricted departmental grants from Research to Prevent Blindness.

\section{Authors' affiliations \\ J M Kim, Keck School of Medicine, University of Southern California, CA, USA \\ L LaBree, Department of Preventive Medicine Statistical Consultation and Research Center, University of Southern California, CA, USA \\ L Levin, S E Feldon, Doheny Eye Institute, University of Southern California, CA, USA \\ S E Feldon, Department of Ophthalmology, Keck School of Medicine, University of Southern California, CA, USA}

Correspondence to: Steven E Feldon, MD, University of Rochester School of Medicine and Dentistry, University of Rochester Eye Institute, 601 Elmwood Avenue, Rochester, NY 14642, USA;

steven_feldon@urmc.rochester.edu

Accepted for publication 26 May 2003

\section{REFERENCES}

1 Doniach D, Florin-Christensen A. Autoimmunity in the pathogenesis of endocrine exophthalmos. Clin Endocrinol Metab 1975;4:341-50.

2 Volpe R. The pathogenesis of Graves' disease: an overview. Clin Endocrinol Metab 1978;7:3-29.
3 Sergott RC, Felberg NT, Savino PJ, et al. The clinical immunology of Graves' ophthalmopathy. Ophthalmology 1981;88:484-7.

4 Perros P, Kendall-Taylor P. Antibodies to orbital tissues in thyroid associated ophthalmopathy. Acta Endocrinol (Copenh) 1992;126:137-42.

5 Gorman CA. Temporal relationship between onset of Graves' ophthalmopathy and diagnosis of thyrotoxicosis. Mayo Clin Proc 1983;58:515-19.

6 Marcocci C, Bartalena L, Bogazzi F, et al. Studies on the occurrence of ophthalmopathy in Graves' disease. Acta Endocrinol (Copenh) 1989; 120:473-8.

7 Solomon DH, Chopra IJ, Chopra U, et al. Identification of subgroups of euthyroid Graves' ophthalmopathy. N Engl J Med 1977;296:181-6.

8 Gorman CA. The presentation and management of endocrine ophthalmopathy. Clin Endocrinol Metab 1978;7:67-96

9 Inoue D, Sato K, Maeda M, et al. Genetic differences shown by HLA typing among Japanese patients with euthyroid Graves' ophthalmopathy, Graves' disease and Hashimoto's thyroiditis: genetic characteristics of euthyroid Graves' ophthalmopathy. Clin Endocrinol 1991;34:57-62.

10 Amino N, Yuasa T, Yabu Y, et al. Exophthalmos in autoimmune thyroid disease. J Clin Endocrinol Metab 1980;51:1232-4.

11 Kasagi K, Hatabu H, Tokuda $Y$, et al. Studies on thyrotrophin receptor antibodies in patients with euthyroid Graves' disease. Clin Endocrinol 1988;29:357-66.

12 Kasagi K, Hatabu $H$, Tokuda $Y$, et al. Comparison of thyroid stimulating activities measured by cyclic AMP production, those by radioiodine uptake in FRTL-5 cells and TSH-binding inhibitory activities in patients with hyperthyroid and euthyroid Graves' diseases. Acta Endocrinol (Copenh) 1988; 117:365-72

13 Salvi M, Zhang ZG, Haegert D, et al. Patients with endocrine ophthalmopathy not associated with overt thyroid disease have multiple thyroid immunological abnormalities. J Clin Endocrinol Metab 1990;70:89-94.

14 Perrild H, Feldt-Rasmussen U, Bech $\mathrm{K}$, et al. The differential diagnostic problems in unilateral euthyroid Graves' ophthalmopathy. Acta Endocrinol (Copenh) 1984;106:471-6.

15 Wiersinga WM, Smit T, van der Gaag R, et al. Clinical presentation of Graves' ophthalmopathy. Ophthalmic Res 1989:21:73-82.

16 National Center for Health Statistics. Serum cholesterol levels among persons 20 years of age and over, according to sex, age, race, and Hispanic origin: United States, 1960-62, 1971-74, 1976-80, and 1988-91. United States, selected years 1965-94. Hyattsville, Maryland: Public Health Service, 1996. (Available from www.cdc.gov/nchs/datawh/statab/pubd/hus-t70h.htm)

17 Centers for Disease Control and Prevention. National diabetes fact sheet: national estimates and general information on diabetes in the United States. Revised edition. Atlanta, GA: US Department of Health and Human Services, Centers for Disease Control and Prevention, 1998. (Available from www.cdc.gov/diabetes/pubs/facts98.htm).

18 National Center for Health Statistics. Hypertension among persons 20 years of age and over, according to sex, age, race, and Hispanic origin: United States, 1960-62, 1971-74, 1976-80, and 1988-91. Hyattsville, Maryland: Public Health Service, 1996. (Available from www.cdc.gov/nchs/datawh/ statab/pubd/hus-t69h.htm)

19 National Center for Health Statistics. Current cigarette smoking by persons 18 years of age and over, according to sex, race, and age: United States, selected years 1965-94. Hyattsville, Maryland: Public Health Service, 1998. (Available from www.cdc.gov/nchswww/datawh/statab/pubd/hust62. htm

20 Bratusch-Marrain P, Schmid P, Waldhausl W, et al. Specific weight loss in hyperthyroidism. Horm Metab Res 1978;10:412-15.

21 Aviram M, Luboshitzky R, Brook JG. Lipid and lipoprotein pattern in thyroid dysfunction and the effect of therapy. Clin Biochem 1982;15:62-6.

22 Hoogwerf BJ, Nuttall FQ. Long-term weight regulation in treated hyperthyroid and hypothyroid subjects. Am J Med 1984;76:963-70

23 Parle JV, Franklyn JA, Cross KW, et al. Circulating lipids and minor abnormalities of thyroid function. Clin Endocrinol 1992;37:411-14.

24 O'Brien T, Katz K, Hodge D, et al. The effect of the treatment of hypothyroidism and hyperthyroidism on plasma lipids and apolipoproteins A1, All and E. Clin Endocrinol 1997:46:17-20.

25 National Center for Health Statistics. Overweight persons 20 years of age and over, according to sex, age, race, and Hispanic origin: United States, 1960-62, 1971-74, 1976-80, and 1988-91. Hyattsville, Maryland: Public Health Service, 1996. (Available from www.cdc.gov/nchswww/datawh/ statab/pubd/hus-t7lh.htm)

26 Prummel MF, Wiersinga WM, Mourits MP, et al. Effect of abnormal thyroid function on the severity of Graves' ophthalmopathy. Arch Intern Med 1990:150:1098-101.

27 Tallstedt L, Lundell $G$, Torring $O$, et al. Occurrence of ophthalmopathy after treatment for Graves' hyperthyroidism. N Engl J Med 1992;326:1733-8.

28 Kung AWC, Yau CC, Cheng A. The incidence of ophthalmopathy after radioiodine therapy for Graves' disease: prognostic factors and the role of methimazole. J Clin Endocrinol Metab 1994:79:542-6.

29 Tallstedt L, Lundell G, Blomgren H, et al. Does early administration of thyroxine reduce the development of Graves' ophthalmopthy after radioiodine treatment? Eur J Endocrinol 1994;130:494-7. 